\title{
RESEARCH ON CROP SIMULATION MODEL BASED ON PDA
}

\author{
Jianbing Zhang ${ }^{1, *}$, Yeping Zhu ${ }^{2}$ \\ ${ }^{1}$ Department of Computer Science and Technology, China University of Petroleum-Beijing, \\ Beijing, China, 102249 \\ ${ }^{2}$ Institute of Agricultural Information, Chinese Academy of Agricultural Sciences, Beijing, \\ China, 100081 \\ * Corresponding author, Address: Department of Computer Science and Technology, China \\ University of Petroleum-Beijing, 18 Fuxue Road, Changping, Beijing, P.R.China 102249 \\ Tel:+86-10-89733009,Email: zhangbing153@yahoo.com.cn
}

\begin{abstract}
Crop model simulates growth and yield of crop in field scale and can be used to provide useful field information for farmers, such as irrigation application dates and amount, fertilizer application dates and amount, the choose of crop variety. Researchers have used crop models for many years, but they have had limited success in packaging these complex models in a framework that make them easy for producers to use. In order to provide an efficient and powerful way for delivering crop models to crop producer, a PDA based crop simulation model is designed and implemented. The paper discussed the structure and key technologies of the PDA based crop model. By using the PDA based crop model, farmers can get quick and effective advices from the model. The PDA based crop models are expected to give a new powerful tool to assess the effect of farm practices in crop production.
\end{abstract}

Keywords: crop model, simulation, visualization, PDA

\section{INTRODUCTION}

The research on crop-environment system began in 60 's. In the past 40 years, it has got great achievements. It was developed from simulation of the basic procedure of crop-environment system $\&$ research of the instantaneous effects to simulation of whole crop-environment system \& research of the

Please use the following format when citing this chapter:

Zhang, J. and Zhu, Y., 2009, in IFIP International Federation for Information Processing, Volume 293, Computer and Computing Technologies in Agriculture II, Volume 1, eds. D. Li, Z. Chunjiang, (Boston: Springer), pp. 585-592. 
interaction of procedures and accumulated effects(Zhu Yeping et al.,2000 ; N.W.T. Quinn et al., 2004). Crop production, farm management and decision making are influenced by a lot of uncertain factors, such as biological and technological ones. Some important decisions in agricultural production, such as irrigation application dates and amount, fertilizer application dates and amount, the choose of crop variety are depended heavily on the existing knowledge base of current environment conditions like soil and climate, water resource(Wang Shiqi,1998). Even in high production level areas such as Beijing, there were also many factors that could not be controlled by people. In order to reach their goals, producers have to take proper measurements according to the information that they had mastered. With the development of agriculture, yield is not the only target, and utilizing resource more reasonably, gaining high yield and high effect with the least investment is took more and more attentions.

Crop model simulates growth and yield of crop in field scale and can be used to provide useful field information for farmers, such as irrigation application dates and amount, fertilizer application dates and amount, the choose of crop variety(Paz, JO and WD Batchelor, 2003). Crop model is an important tool to make quantitative analysis of the crop-environment system. It can be used in different situations, and can provide various information about the system to different users, especially in providing the agricultural technical personnel with production information. It can be used to predict those factors that could not be controlled. It can help to decide the irrigation measurement and fertilization measurement according to special target such as high yield, maximal profit.

Due to the complexity of crop-environment system, the limit of agricultural data collection and some technology restrictions, crop model techniques have not been widely applied in agricultural production. Researchers have used crop models for many years, but have had limited success in packaging these complex models in a framework that make them easy for producers to use.

In recent years, PDA developed very rapidly. The function of the operating system of PDA was even stronger, and there were several tools supporting PDA application development. It is possible to the development of the agriculture-based Pocket PC applications. In order to provide an efficient and powerful way for delivering crop models to crop producer, wheat and corn crop models based on PDA are designed and implemented. The paper discussed the structure and key technologies of the PDA based crop model. By using the PDA based crop model, farmers can get quick and effective advices from the model. The PDA based crop models are expected to give a new powerful tool to assess the effect of farm practices in crop production. 


\section{DESIGN OF THE CROP SIMULATION MODEL BASED ON PDA}

PDA based crop model is composed of parameter management module, GPS module, simulation module, decision module and visualization of crop growth module. The basic functions of the system are shown as fig 1 . The parameter management module is important part of the system as model input. While some parameters are input to model by hand, and some parameters of the model can be acquired with the GPS information. After position information of the simulation place is received by GPS receiver, we can send parameter search request to the backend server, for example, we can send the place position to weather databases to get the weather information.

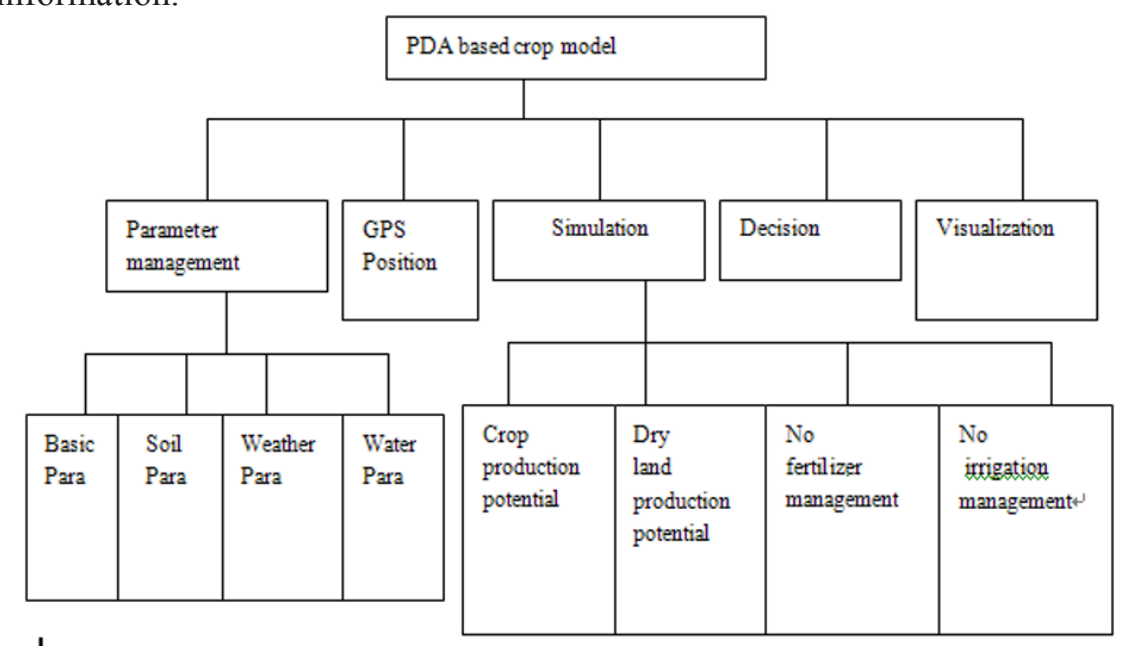

Fig. 1: Basic functions of the system

Crop simulation model can simulate in several environments such as crop production potential, dry land production potential, no fertilizer management etc. According to different goals, decision module can provide optimum plant measurement. In order to make uses understand the crop growth stages better, the system provides visible crop growth simulation.

The architecture of the system is based on multi-layers architecture. The system is composed of three layers: the user interface layer, the service layer, and the database layer. The architecture of the system is as Fig 2: 


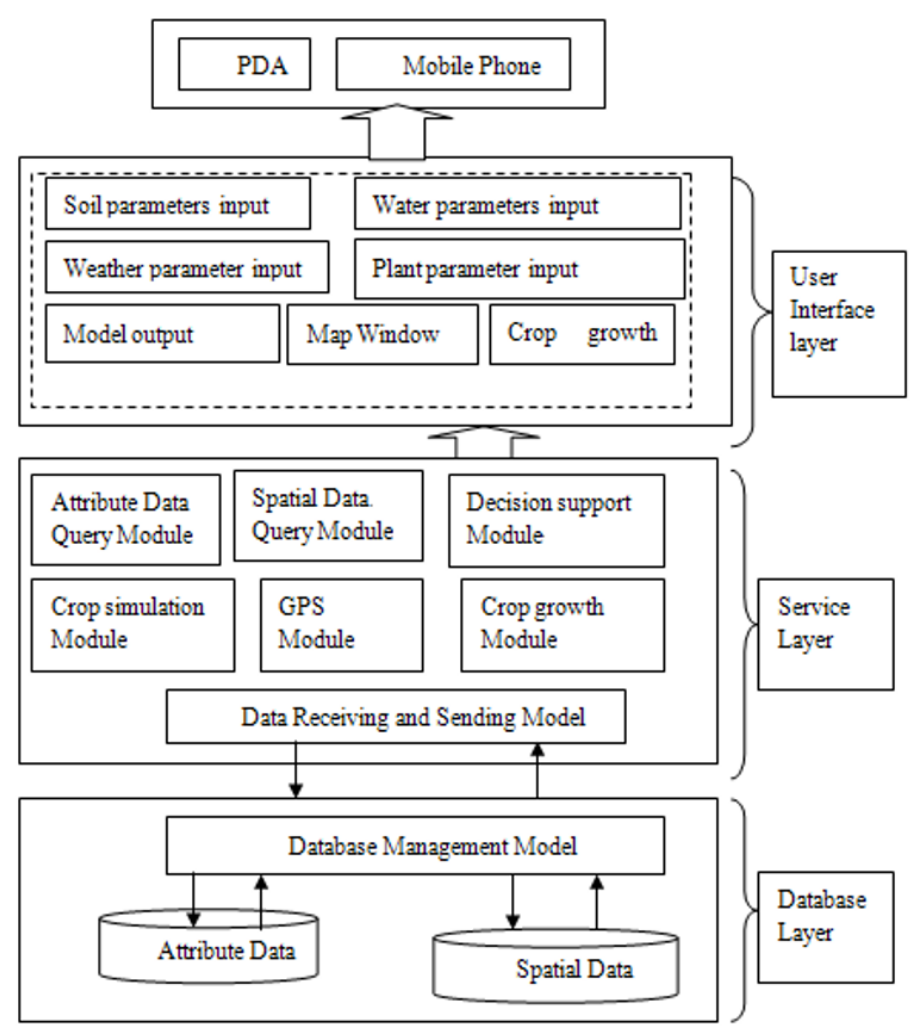

Fig.2: Architecture of PDA based crop simulation system

\section{KEY TECHNOLOGIES OF THE SYSTEM}

In order to achieve crop production simulation at $4 \mathrm{~A}$ (anytime, anywhere, anybody, anything), the system applies embedded programming technology, GPS technology, database technology, crop growth visualization and crop simulation technology. The integration of GPS technology makes parameter acquiring more convenient. The database technology in PDA makes data management easy and effective. The visualization technology of crop growth makes users understanding easily.

\subsection{Integration of GPS positioning}

GPS module is responsible for accepting GPS data. By serial communication programming, the current position coordinate can be acquired and parsed in the system. The basic units (water, soil and weather data) of crop models have a spatial distribution. Spatial variability of crop production 
such as different soil conditions, weather conditions and water conditions needs different agricultural production management practices within a targetregion. With the position coordinate, we can get the spatial information and property information of the current field. With the combination of GPS technology, some model inputs can be imported to the system and we need not to input every model parameter in the system. And also GPS position can be integrated with GIS functionalities, they will provide more conveniences for crop simulation and analysis.

\subsection{Crop simulation model}

Crop simulation model is the key part of the system. It is the result of many years' research in wheat and corn simulation by Yeping zhu, Shiqi wang in CAAS(Chinese Academy of Agricultural Science). The research was supported by Chinese Academy of Agricultural Science and National 863 project of China. The models require inputs including environmental conditions (soil type, daily maximum and minimum temperature, rainfall, and solar radiation) and management practices (variety, row spacing, plant population). The simulation result includes daily growth of vegetative, stage, and water and nitrogen stress. The model provided decisions and supports to the below practical questions: the choose of spices in wheat-corn continuous cropping condition, the reasonable use of the resource, best use of the limited water resource, distributing the limited $\mathrm{N}$ fertilizer to maximal profit. In our research we focuses on the migration of crop models from Windows desktop to WinCE.

\section{3 visualization of crop growth}

The visualization of crop growth includes the visualization of root, stem, leaf and grain. The shape of single crop is displayed on the screen everyday according to the result of the simulation. In order to implement visualization of the crop during growth stage, we adopt object oriented programming. We designed CRoot, CLeaf, CLitter,CGrain classes. Every class is responsible for its visual expression. The whole crop visual expression is composed of all its parts. During the visual expression of crop growth, firstly we got the leaf, root, litter and grain parameter values, then put those values to relative object of correspondent class. Then the dynamic growth process can be displayed. The visibility technology of crop growth makes the model more conveniently to use.

\subsection{Database}

The development of this system is based on Windows CE operating system. Currently the database can be used on Windows CE includes Pocket Access, 
SQL Server CE, Oracle Lite and so on. Since SQL Server CE has been able to implement most of the SQL query processing, support for most of SQL statements, and made a lot of optimization to accelerate the speed of the implementation of SQL statements, we choose to use the SQL Server CE to store model parameters and output.

There are three kinds of database development technologies in Windows CE platform: using database application programming interface (API) provided by Windows CE, using ActiveX Data Objects (ActiveX Data Objects, ADO) interface or use OLEDB interface. Considering development of difficulty and speed of response, we choose to use ADO CE development technology. Crop simulation database includes basic parameters table, irrigation data table, fertilization table, the weather data, soil parameters table, crop varieties table and so on.

\section{IMPLEMENTATION}

The PDA based crop simulation system is developed under the condition of Windows CE desktop, the local database is adopt SQL server CE, and the development tool is Microsoft Windows CE Toolkit for Visual $\mathrm{C}++(\mathrm{eVC})$. ADOCE technology is used in the system to access database. GPS module programming uses serial communication technology. After receiving the data from the COM port, it should be parsed to get the position coordinate. The visualization of crop growth used object oriented design and implementation.

Some of running results of the system are as follow:

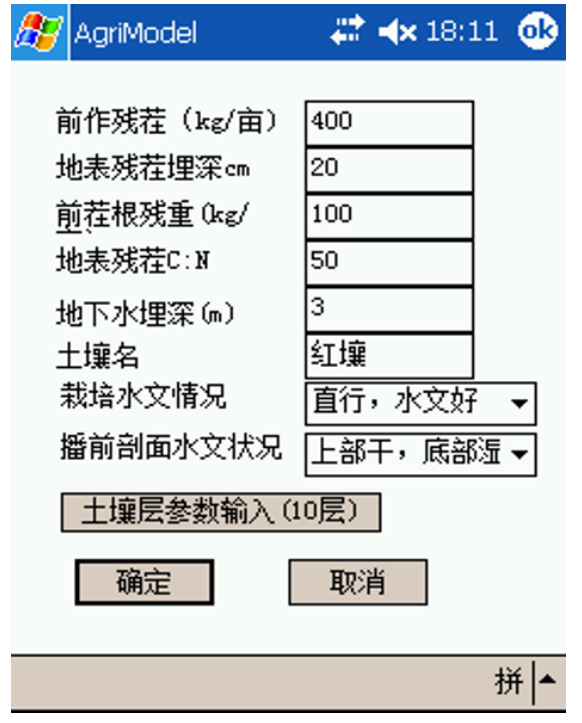

Fig. 3.Soil parameter input interface
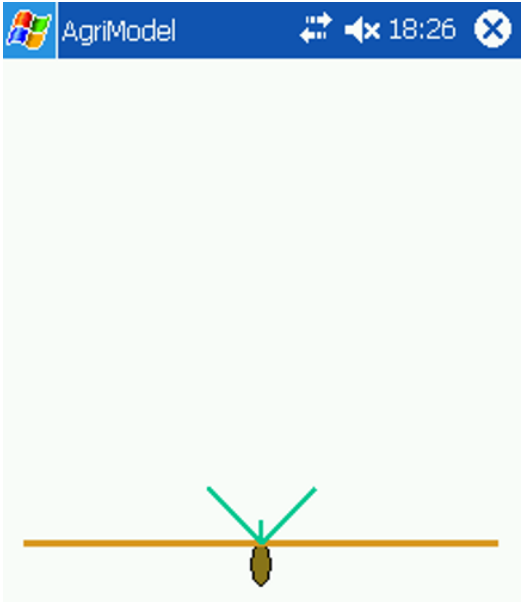

系统 模拟内容生长演示 帮助 $\mid \square$ 匹拼| 

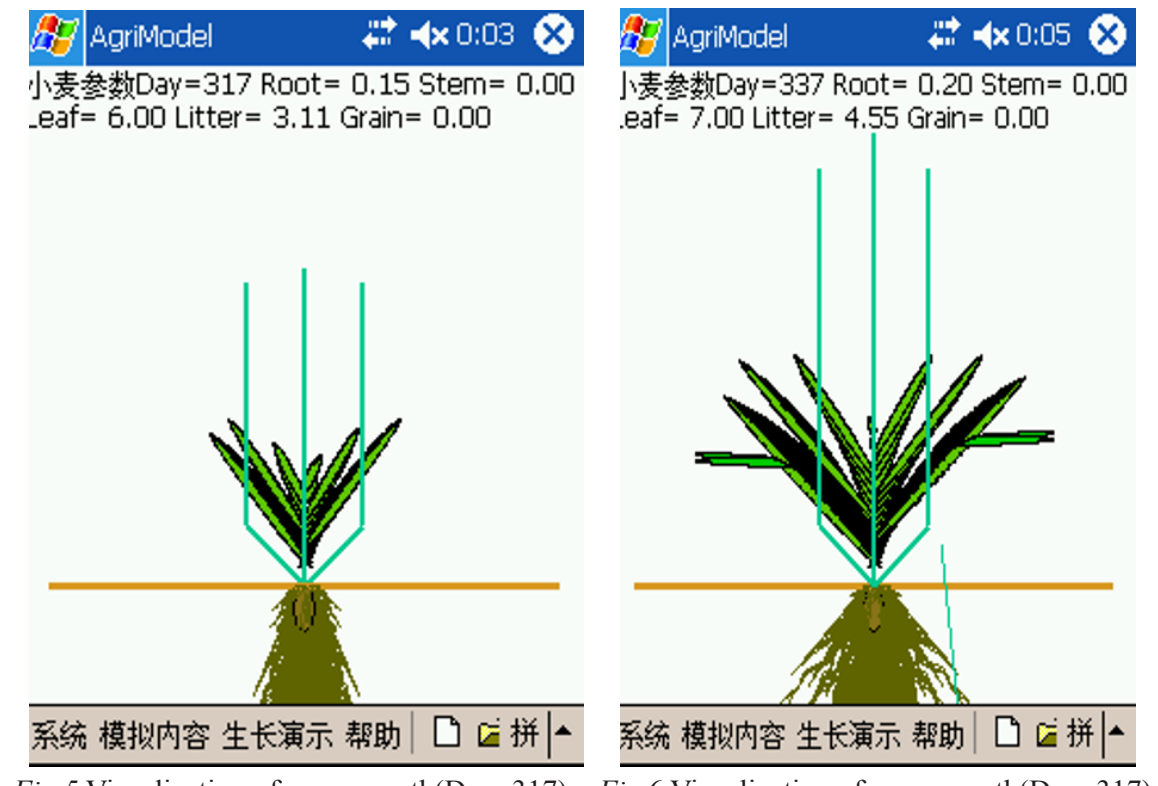

Fig. 5 Visualization of crop growth(Day=317) Fig.6 Visualization of crop growth(Day=317)

\section{CONCLUSION}

PDA based crop models are expected to give a new approach to provide agricultural managers with a powerful tool to assess simultaneously the effect of farm practices to crop production. In this study, a system framework is designed using three-tier architecture, and crop models are packaged and migrated to PDA. The graphical display of wheat and corn model results, visualization of crop growth and decision of crop production are also achieved in the system. The study successfully demonstrated the integration of crop model with embedded technology, GPS technology and its application in crop production management. With the support of embedded technology, crop models will be easy to use in crop production.

\section{ACKNOWLEDGEMENTS}

This research was supported by National Scientific and Technical Supporting Programs Funded by Ministry of Science and Technology of China(2006BAD10A06), and Digital Agriculture Program of State Hightech Research and Development Project of China(No. 2006AA10Z220). 


\section{REFERENCES}

Hunt L.A., Data Requirements for Crop Modeling, P.F. Uhlir and G.C. Carter Editors: Crop Modeling and Related Environmental Data. 1994.

N.W.T. Quinn, L.D. Brekke, K.L. Bashford, N.L. Miller,H. Hidalgo, P. Raju and J.A. Dracup Model Integration For Assessing Future Hydroclimate Impacts On Water Resources, Agricultural Economic Sustainability And Environmental Quality in the San Joaquin Basin, California, Environmental Modelling \& Software, Volume 19, Issue 3, March 2004, Pages 305-316.

Paz, JO and WD Batchelor. 2003:Web-based soybean yield simulation model to analyze the effects of interacting yield-limiting factors variations of winter time air pollution concentrations in the city of Graz, Austria. Environmental Monitoring and Assessment, 2001, 65: 79-87. ASAE Paper No. 033150. Paper presented at the 2003 ASAE Annual International Meeting.

Wang Shiqi Zhu Yeping etc., A System Framework Based on Crop Simulator, Modeling for Crop-Climate-Soil-Pest System and Its Applications in Sustainable Crop Production 1998.6.

Yeping Zhu,Jianbing Zhang,Shijuan Li,Ling Xue,Shengping Liu,Yan xue, Application of Agent in Agricultural \& Forestry Economy decision support system, 《New Zealand Journal of Agricultural Research》2007, Vol. 50: 1339-1346

Zhang jianbing, Integrating Crop Simulation Models with WebGIS for Remote Crop Production Management, 2004 IEEE International Geoscience and Remote Sensing Symposium.

Zhu Yeping, Zhang Jianbing, et al; Intelligent Simulation System of Wheat-Corn Continuous Cropping and Environment [M];International Symposium On Intelligent Agricultural Information Technology; 2000. 